\title{
Orbital apex syndrome associated with fractures of the inferomedial orbital wall
}

This article was published in the following Dove Press journal:

Clinical Ophthalmology

4 March 2013

Number of times this article has been viewed

\section{Akira Sugamata \\ Department of Plastic and Reconstructive Surgery, Tokyo Medical University Hachioji Medical Center, Tokyo, Japan}

\begin{abstract}
Although trauma is one of the main causes of orbital apex syndrome (OAS), reports of OAS associated with orbital fractures are relatively rare. We recently treated two patients who sustained severe visual impairment with damage to multiple cranial nerves (third to sixth) associated with inferomedial orbital wall fractures. In these patients, posterior movement of the globe caused neuropathy of the cranial and optic nerves by posterior globe edema and hemorrhage, or direct impact between the globe and wall, which might then have induced OAS in the cases described in this report. Steroid therapy was unsuccessful for optic neuropathy due to the delay between injury and administration. When treating patients with inferomedial orbital blowout fractures due to globe-to-wall contact, it is necessary to routinely assess and monitor visual acuity since there may be a delay between the injury and OAS onset.

Keywords: orbital apex syndrome, orbital fracture, blowout fracture, optic nerve, globe-to-wall contact mechanism
\end{abstract}

\section{Introduction}

Orbital apex syndrome (OAS) has been described as a syndrome involving damage to the oculomotor nerve (third), trochlear nerve (fourth), ophthalmic branch of the trigeminal nerve (fifth), and the abducens nerve (sixth), in association with optic nerve dysfunction. ${ }^{1}$ OAS may be caused by neoplasia, inflammation, viral and fungal infections, trauma, or vascular disorders. Although trauma is one of the main causes, ${ }^{2}$ reports of OAS associated with facial bone fractures are relatively rare. ${ }^{3-7}$ We recently treated two patients who sustained severe visual impairment with damage to multiple cranial nerves (third to sixth) associated with inferomedial orbital wall fractures. The present report aimed to evaluate treatment of OAS associated with orbital fractures, which remains controversial.

\section{Case reports Case I}

A 73 year old woman sustained an injury to the left periorbital area when she fell to the ground. She was examined in ophthalmic department of Tokyo Medical University Hospital on the same day. Her computed tomogram (CT) showed a fracture to the left orbital medial wall. Her ocular movement showed no abnormality and her left direct light reflex was slightly weaker than normal. Her visual acuity was 20/100 (right eye) and 20/32 (left eye); however, the ophthalmologist did not notice disturbance of the left optic nerve during the first examination, therefore the patient returned home without 
treatment. After she returned home, visual acuity of her left eye gradually decreased. She returned to the ophthalmic and the plastic surgery department 7 days after injury, displaying ptosis of the left upper eyelid (pupil fixed and dilated), ophthalmoplegia, and reduced left visual acuity (light perception). Her CT showed displacement of the left posterior inferomedial wall; there was no fracture in the optic foramen (Figure 1). The fundoscopic findings showed an edematous retina, small bleeding sites along the retinal artery, and regional ischemic changes, which caused obstruction of the central retinal artery (Figure 2). She was diagnosed with OAS associated with a blowout fracture to the inferomedial wall. She was treated with administration of betamethasone sodium phosphate (4 mg) and an osmotic diuretic agent for 2 days. Betamethasone reduced to $2 \mathrm{mg}$ was continued for the following 6 days. During this period, stellate ganglion blockade was administered five times. Subsequently, at follow-up she was administered vitamin $B_{12}$ as an outpatient. Six months after the injury, ptosis and ocular movement improved; however, there was no improvement in visual acuity. She showed left enophthalmos (3 mm); however, she did not express interest in undergoing reconstructive surgery (Figure 3 ).

\section{Case 2}

A 59 year old man sustained facial and ocular injuries in an automobile accident. In the emergency section of a different hospital, he underwent surgical repair of a laceration to his left upper eyelid. The CT showed a fracture of the left orbit that included the inferomedial wall and the floor (Figure 4). Fundoscopic examination did not reveal any useful findings due to bleeding in the vitreous body. Three days after the injury, he was referred to our department for repair of his orbital fracture. Upon physical examination, his left upper eyelid was swollen and drooping, and he was unable to see even when the ptotic upper eyelid was lifted by his finger. Extraocular movement of the left globe was limited in all directions, and the pupil was dilated and fixed (Figure 5).

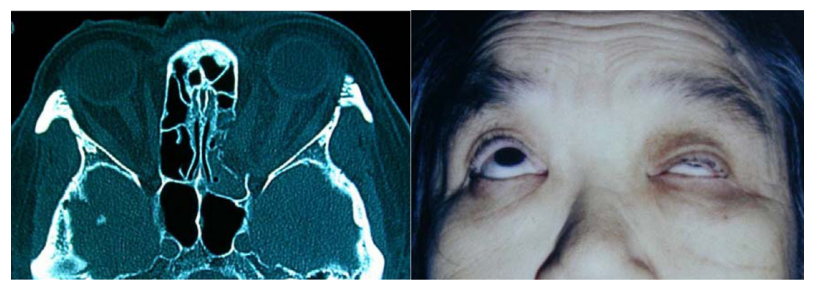

Figure I Computed tomogram and photograph of Case I.

Notes: A 73 year old woman was injured in the left periorbital area when she fell to the ground. The computed tomogram showed displacement of the left inferomedial wall. She subsequently suffered ptosis of the left upper eyelid, with a fixed and dilated pupil, ophthalmoplegia, and weakness of her left visual acuity.

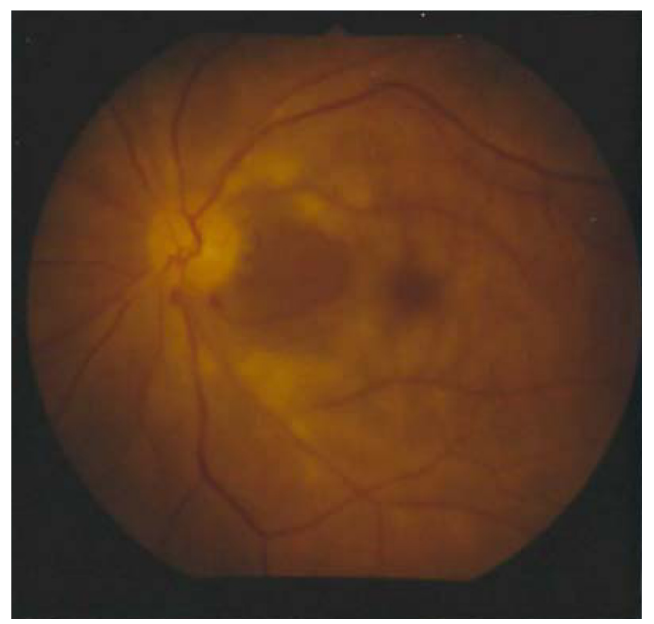

Figure 2 Fundoscopic image of Case I.

Notes: Fundoscopy revealed an edematous retina, small bleeding sites along the retinal artery and regional ischemic changes, which caused disturbance of the central retinal artery.

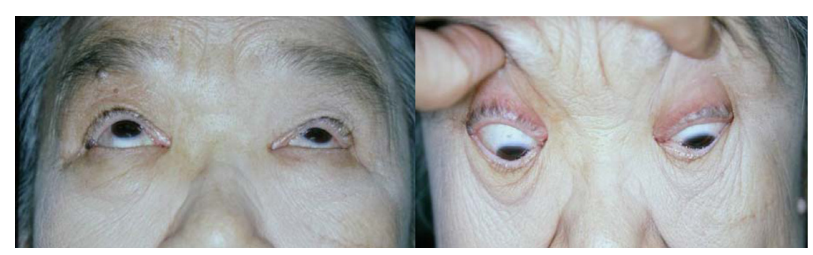

Figure 3 Photographs 6 months after injury in Case I.

Notes: Six months after injury, the patient's ptosis and ocular movement improved; however, there was no improvement in visual acuity. She displayed left enophthalmos $(3 \mathrm{~mm})$; however, she did not express interest in reconstructive surgery.

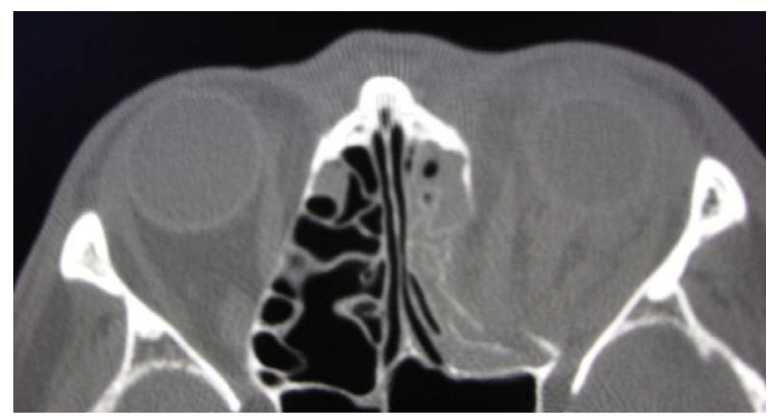

Figure 4 Computed tomogram from Case 2.

Notes: Case 2, a 59 year old man, sustained a left inferomedial and floor orbital fracture in a motor vehicle accident. The computed tomogram showed wide displacement of the left inferomedial wall and floor.

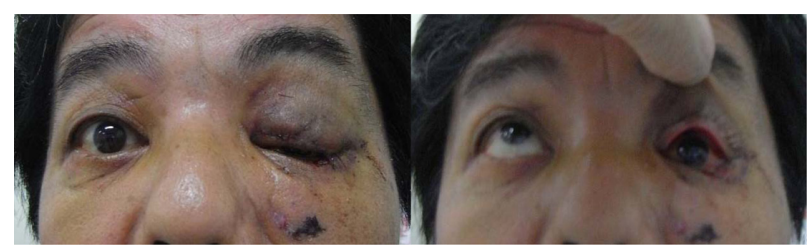

Figure 5 Case 2, 3 days after trauma.

Notes: On post trauma day 3 , the patient's left eyelid was drooping and extra ocular movement of the left globe was limited in all directions. The pupil was dilated and fixed and his left visual acuity was restricted to counting fingers. 
Left visual acuity was limited to finger counting, and right visual acuity was 20/25. Ophthalmologic examination revealed vitreoretinal hemorrhage. He was diagnosed with OAS associated with the blowout fracture to his left orbit. We identified no indication of early reconstruction of his orbital fracture, and selected conservative therapy for OAS. After gaining experience from the first case (Case 1, above), we deemed steroid administration at this point to be too delayed to obtain a good result, and followed up the patient with vitamin $\mathrm{B}_{12}$ only. One year post injury, eye movement had become possible in all directions; however, the left upper lid ptosis did not completely resolve. There has been no improvement in his left visual acuity. Reconstruction of his enophthalmos (4 $\mathrm{mm})$ is planned after complete resolution of his lid ptosis (Figure 6).

\section{Discussion}

Orbital apex syndrome is a rare condition resulting from one or more of a range of pathological processes surrounding the optic nerve foramen and the superior orbital fissure, causing characteristic functional loss. OAS is characterized by ophthalmoplegia, lid ptosis, proptosis, a fixed and dilated pupil due to damage of multiple cranial nerves (third to sixth) that pass through the superior orbital fissure, and also by reduced visual acuity due to disturbance of the optic nerve. Trauma is one cause of OAS; however, reports of OAS with orbital fractures were rare. We found only 17 reported cases in the literature, with the locations of fractures as follows: seven medial wall; seven lateral wall; one floor; one roof; one floor and roof (Table 1). ${ }^{3-7}$ In the majority of these cases, small fractures were detected around the optic canal and the superior orbital fissure at the orbital apex. However, in our two cases, fractures were found in the inferomedial area of the orbital wall and the size and shape of the displacement of the orbital

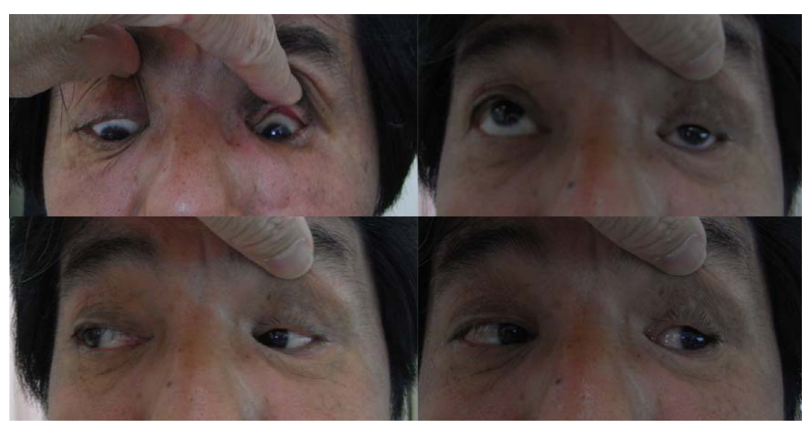

Figure 6 Photographs of eye movements I year after injury in Case 2.

Notes: One year after injury, eye movement became possible in all directions; however, the left upper lid ptosis did not improve completely. There has been no improvement in his left visual acuity. We are planning a reconstruction of his enophthalmos $(4 \mathrm{~mm})$ after his lid ptosis completely resolves.
Table I Fracture sites in OAS $(\mathrm{n}=17)$

\begin{tabular}{ll}
\hline Site of fracture & Number \\
\hline Medial wall & 7 \\
Lateral wall & 7 \\
Floor & $\mathrm{I}$ \\
Roof & $\mathrm{I}$ \\
Floor and roof & $\mathrm{I}$ \\
\hline
\end{tabular}

Abbreviation: OAS, orbital apex syndrome.

wall conformed to the shape of the globe. These fractures were likely due to a globe-to-wall contact mechanism. ${ }^{8}$ Posterior movement of the globe led to neuropathy of the cranial and optic nerves by posterior globe edema and hemorrhage or direct impact between the globe and wall, ${ }^{9,10}$ which may have caused OAS in our cases. We believe these particular occurrence mechanisms of OAS to be very rare.

In treatment of OAS associated with orbital fractures, there are three different therapeutic targets: the globe; the third to sixth cranial nerves; and the optic nerve. The globe is highly vulnerable to permanent injury after orbital fractures. Hyphema, lens or retinal detachment, and scleral rupture may all occur at the time of impact and lead to permanent vision loss. Early ophthalmologic consultation is essential in all cases of orbital fractures.

In many reviews of superior orbital fissure syndrome associated with fractures, prognosis of disturbance of the third to sixth cranial nerves is good. ${ }^{11-13}$ Unless the nerves have been seriously damaged, complete recovery of sensory and motor functions usually occurs without surgical exploration. In our cases, disturbance of ocular movement and ptosis of the upper lid also improved. Patients with evidence of direct compression of cranial nerves by orbital fractures should undergo surgical treatment; however there are no clearly defined indications, nor optimum timing, for this procedure. ${ }^{12,13}$

The management of traumatic optic neuropathy associated with OAS is highly important and remains controversial. Shearing forces after fractures can be great enough to transect the nerve, leading to immediate and irreversible blindness. There is no indication for treatment of the optic nerve in these cases.

Delayed and progressive loss of vision implies that a viable nerve is being compressed by edema and bleeding; in such cases, early treatment may improve recovery prospects. ${ }^{14}$ Nonoperative intervention may consist of administration of high doses of corticosteroids to reduce microcirculatory spasm, edema, and nerve cell necrosis. ${ }^{14,15}$ However, the best results are achieved if steroids are given immediately after injury because irreversible ischemic damage often occurs within several hours. In our first case, steroid therapy was 
unsuccessful, because the time between injury and administration was too great.

Surgical decompression of the optic canal is believed to reduce the sequelae of edematous compression of the optic nerve and its vascular supply within the optic canal. ${ }^{16,17}$ Decompression may theoretically play an important role when visual loss is associated with a fracture of the optic canal, or if a bone fragment impinges the optic nerve. However, in our two cases, there was no fracture in the optic canal and no bone impingement to the nerve. The mechanism of the blowout fractures of these cases suggested that the retrobulbar optic nerve located in the orbital apex had been injured but it was very difficult to determine whether we should surgically intervene. Li et $\mathrm{al}^{6}$ describe nasal endoscopic decompression of the superior and medial walls of the orbital apex in the early stages following injury as an effective treatment to preserve visual acuity in OAS. However, in our cases, the orbital apex was already decompressed with wide displacement of the inferomedial wall; operative management in these circumstances may induce more edema and hemorrhage in the posterior area of the orbit. In cases such as those reported here, administration of high doses of corticosteroid therapy should be selected in the early stages post injury when visual acuity is decreasing.

To decide the exact timing of the administration of high doses of corticosteroids, accurate and reliable evaluation of optic nerve function is essential. ${ }^{18}$ Visual testing is the most appropriate clinical evaluation and permits early detection and treatment of OAS; however, in our second patient with bleeding of the vitreous body, it was difficult to accurately evaluate visual acuity. In these instances, the presence of a Marcus Gunn pupil is pathognomonic for afferent optic nerve injury. ${ }^{19}$ In conclusion, when treating patients with inferomedial orbital blowout fractures due to globe-to-wall contact, it is advisable for both the plastic surgeon and the ophthalmologist to routinely assess and monitor visual acuity, with the recognition that there may be a delay between injury and the development of OAS.

\section{Acknowledgments}

The patients provided written consent for the use of their images.

\section{Clinical Ophthalmology}

\section{Publish your work in this journal}

Clinical Ophthalmology is an international, peer-reviewed journal covering all subspecialties within ophthalmology. Key topics include: Optometry; Visual science; Pharmacology and drug therapy in eye diseases; Basic Sciences; Primary and Secondary eye care; Patient Safety and Quality of Care Improvements. This journal is indexed on Submit your manuscript here: http://www.dovepress.com/clinical-ophthalmology-journal

\section{Disclosure}

The author reports no conflicts of interest in this work.

\section{References}

1. Yeh S, Foroozan R. Orbital apex syndrome. Curr Opin Ophthalmol. 2004;15(6):490-498.

2. Peter NM, Pearson A. Orbital apex syndrome from blunt ocular trauma. Orbit. 2010;29(1):42-44.

3. Bernard A, Sadowsky D. Monocular blindness secondary to a nondisplaced molar fracture. Int J Oral Maxillofac Surg. 1986;15(2): 206-208.

4. Acartürk S, Dalay C, Kivanc Ö, Varinli I. Orbital apex syndrome associated with fractures of the zygoma and orbital floor. Eur J Plast Surg. 1993;16(2):67-69.

5. Martello JY, Vascionez HC. Supraorbital roof fractures: a formidable entity with which to contend. Ann Plast Surg. 1997;38(3):223-227.

6. LiY, Wu W, Xiao Z, Peng A. Study on the treatment of traumatic orbital apex syndrome by nasal endoscopic surgery. Eur Arch Otorhinolaryngol. 2011;268(3):341-349.

7. Bater MC, Ramchandani PL, Ramchandani M, Flood TR. An orbital apex fracture resulting in multiple cranial neuropathies. $\mathrm{Br} J$ Oral Maxillofac Surg. 2008;46(2):163-164.

8. Sugamata A, Yoshizawa N. Clinical analysis of orbital blowout fractures caused by a globe-to-wall contact mechanism. J Plast Surg Hand Surg. 2010;4(6):278-281.

9. Kang BD, Jang MH. A case of blowout fracture of the orbital wall with eyeball entrapped within the ethmoid sinus. Korea J Ophthalmol. 2003; 17(2):149-153.

10. Himori N, Kumikata H, Otomo T, Fuse N, Nishida K. Central retinal artery occlusion following severe blow-out fracture in young adult. Clin Ophthalmol. 2009;3:325-328.

11. Zachariades N, Vairaktaris E, Papavassiliou D, Papademetriou I, Mezitis M, Triantafyllou D. The superior orbital fissure syndrome. J Maxillofac Surg. 1985;13(3):125-128.

12. Chen CT, Wang TY, Tsay PK, Huang F, Lai JP, Chen YR. Traumatic superior orbital fissure syndrome: assessment of cranial nerve recovery in 33 cases. Plast Reconstr Surg. 2010;126(1):205-212.

13. Kurzer A, Patel MP. Superior orbital fissure syndrome associated with fractures of the zygoma and orbit. Plast Reconstr Surg. 1979;64(5): 715-719.

14. Lipkin IF, Woodson GE, Miller RH. Visual loss due to orbital fracture. The role of early reduction. Arch Otolaryngol Head Neck Surg. 1987;113(1):81-83.

15. Eo S, Kim JY, Azari K. Temporary orbital apex syndrome after repair of orbital wall fracture. Plast Reconstr Surg. 2005;116(5):85e-89e.

16. Li KK, Teknos T, Lai A, Lauretano AM, Joseph MP. Traumatic optic neuropathy: result in 45 consecutive surgically treated patients. Otolaryngol Head Neck Surg. 1999;120(1):5-11.

17. Cook MW, Levin LA, Joseph MP, Pinczower EF. Traumatic optic neuropathy. A meta-analysis. Arch Otolaryngol Head Neck Surg. 1996;122(4):389-392.

18. Soparkar CN, Patrinely JR. The eye examination in facial trauma for the plastic surgeon. Plast Reconstr Surg. 2007;120:7(Suppl 2):49s-56s.

19. Girotto JA, Gamble WB, Robertson B, et al. Blindness after reduction of facial fractures. Plast Reconstr Surg. 1998;102(6):1821-1834.

\section{Dovepress}

PubMed Central and CAS, and is the official journal of The Society of Clinical Ophthalmology (SCO). The manuscript management system is completely online and includes a very quick and fair peer-review system, which is all easy to use. Visit http://www.dovepress.com/ testimonials.php to read real quotes from published authors. 